\title{
Perfil sociodemográfico e estilo de vida de trabalhadores de uma indústria metalúrgica
}

\author{
Socio-demographic profile and lifestyle of workers of a metallurgical industry
}

Perfil socio demográfico y estilo de vida de trabajadores de una industria metalúrgica

\author{
Maria Raquel Brazil Battaus', Maria Inês Monteiro' \\ 'Universidade Estadual de Campinas, Faculdade de Ciências Médicas, Departamento de Enfermagem. Campinas-SP, Brasil.
}

Submissão: 12-07-2011 Aprovação: 23-02-2013

\section{RESUMO}

Estudo epidemiológico transversal realizado em indústria metalúrgica, no interior do estado de São Paulo, com o objetivo de identificar o perfil sociodemográfico, aspectos de saúde, como índice de massa corporal, horas de sono, tabagismo, etilismo e estilo de vida dos trabalhadores. Foram entrevistados 182 trabalhadores que responderam questionário com dados sociodemográficos, estilo de vida e saúde. A maioria era do sexo masculino $(75,8 \%)$, com idade média de 33,8 anos, realizava atividade de lazer $(88,5 \%)$ e fazia hora extra $(72,5 \%)$. Faziam atividade física $(55 \%)$; fumavam $(17,6 \%)$ e relataram ingestão de bebida alcoólica $(59,3 \%)$. A investigação dos aspectos de saúde e trabalho é de grande importância visando à implantação de medidas de proteção e prevenção relacionadas ao trabalho e à vida pessoal de cada trabalhador.

Descritores: Saúde do Trabalhador; Saúde; Trabalho; Estilo de Vida; Metalurgia.

ABSTRACT
This is a cross-sectional study, carried out in a metallurgical industry in the state of São Paulo, Brazil, aiming to identify the demographic profile, health aspects such as body mass index, hours of sleep, smoking, alcohol consumption and lifestyle of the workers. We interviewed 182 workers who answered a questionnaire with socio-demographic, lifestyle and health. The majority was male $(75.8 \%)$, with a mean age of 33.8 years, did leisure activities $(88.5 \%)$ and did overtime $(72.5 \%)$. Physical activity was referred by $55 \%$ of the workers, $17.6 \%$ smoked and $59.3 \%$ reported drinking alcohol. The investigation of health and work aspects is important in order to implement prevention and protection measures related to work and the personal life of each worker.

Key words: Occupational Health; Health; Work; Life Style; Metallurgy.

\section{RESUMEN}

Estudio epidemiológico realizado en una industria metalúrgica en el estado de São Paulo, Brasil, con el objetivo de identificar el perfil socio demográfico, aspectos de la salud, tales como el índice de masa corporal, horas de sueño, el tabaquismo, el consumo de alcohol y estilo de vida de trabajadores. Entrevistamos a 182 trabajadores que respondieron a un cuestionario con el estilo de vida socio demográficas y de salud. La mayoría eran hombres (75,8\%), con edad media de 33,8 años, oscilando, actividades de ocio (88,5\%) y que las horas extraordinarias (72,5\%). La actividad física fue de 55\%, el 17,6\% fumaba y el 59,3\% dijeron haber bebido alcohol. La investigación de los aspectos de la salud y el trabajo es de gran importancia para la aplicación de las medidas de prevención y protección relacionadas no sólo trabajo, sino también la vida personal de cada trabajador.

Palabras clave: Salud Laboral; Salud; Trabajo; Estilo de Vida; Metalurgia. 


\section{INTRODUÇÃO}

Promover a saúde e prevenir os riscos no ambiente de trabalho exige intervenção multidisciplinar. Entretanto, tal preocupação nem sempre está presente em todos os ambientes de trabalho.

A Política de Saúde do Trabalhador, proposta pelo Sistema Único de Saúde (SUS), que inclui ações e serviços de saúde no sistema público e privado, apesar de demonstrar avanços na legislação e práticas institucionais na área, apresenta ainda dificuldades e lacunas. São necessárias alternativas que contribuam na transformação desse contexto a fim de superar a concepção reducionista do processo saúde/doença, que desconsidera a subjetividade e propor um novo modelo de articulação entre promoção da saúde e trabalho(1).

Acidentes e doenças do trabalho merecem atenção, pois trazem prejuízos para o trabalhador e para o empregador, além de afetarem a economia do país( ${ }^{(2)}$ e incidirem diretamente nos serviços de saúde.

Ressalta-se que o trabalhador, para realizar suas atividades, deve ter condições ambientais adequadas, não devendo exceder os limites de resistência ${ }^{(3)}$. O Ministério do Trabalho exige avaliação periódica dos riscos do ambiente de trabalho e da saúde dos trabalhadores, cujos resultados devem subsidiar os programas de prevenção como o Programa de Prevenção de Riscos Ambientais - PPRA (Norma Regulamentadora 9) e o Programa de Controle Médico de Saúde Ocupacional - PCMSO (Norma Regulamentadora 7), que são obrigatórios para as empresas ${ }^{(4)}$.

Os acidentes de trabalho estão presentes no cotidiano das empresas, incluindo-se as metalúrgicas, nas quais existe grande número de relatos de acidentes e doenças relacionadas ao trabalho que merecem destaque.

Autores $^{(2-3,5-6)}$ relacionaram a surdez, patologia bastante encontrada nas metalúrgicas ao ruído presente nesses ambientes de trabalho. Em relação a isso, em outubro de 2005 durante a semana da Saúde e Segurança no Trabalho da União Européia, foi discutido como tema a ênfase nos problemas referente ao ruído no local de trabalho(7).

Pesquisa $^{(8)}$ evidenciou a prevalência de sintomas auditivos e vestibulares em trabalhadores expostos ao ruído ocupacional. Outro estudo ${ }^{(9)}$ também mostrou os efeitos auditivos causados pela exposição combinada ao monóxido de carbono e ao ruído em operadores de empilhadeira.

É sem dúvida importante o estudo de tais trabalhadores já que se tem observado um grande número de investigações que relacionam perda auditiva em trabalhadores, sendo esse um assunto extremamente importante quanto aos problemas de saúde de metalúrgicos.

Não só a perda auditiva é encontrada com frequência em tais tipos de empresas, mas também os acidentes de trabalho, em geral.

Investigação(2) identificou a alta frequência de acidentes de trabalho nas indústrias metalúrgicas não somente relacionados aos fatores de riscos ambientais, como ruído e maquinário sem proteção, como também quanto a disfunção organizacional.
Além dos acidentes de trabalho que merecem destaque é importante salientar que "a exposição prolongada às condições inadequadas expõe o trabalhador a distúrbios musculoesqueléticos e outras doenças ocupacionais responsáveis por um grande número de afastamentos do trabalho, tendo influencia direta na sua qualidade de vida e capacidade laborativa"(10).

Cabe destacar que a promoção da saúde engloba a adoção de medidas que reduzam os riscos de adoecimentos assim como envolve a melhoria da qualidade de vida. Assim, uma ampla abordagem é proposta, por meio do estudo do ser humano no trabalho, resultando em estratégia nova e integrada, que é a relação das pessoas e organizações saudáveis ${ }^{(11)}$.

Tendo em vista as pesquisas no ramo metalúrgico realizadas nas últimas décadas, é indispensável à discussão das formas de melhoria das condições de trabalho, isto é, quais as estratégias e intervenções podem ser feitas para que tais agravos à saúde do trabalhador sejam prevenidos ou minimizados.

\section{OBJETIVO}

Identificar o perfil dos trabalhadores metalúrgicos quanto ao sexo, idade, estado civil, escolaridade, ocupação, número de filhos, atividade física e de lazer; e aspectos de saúde como índice de massa corporal, horas de sono, tabagismo, etilismo; aspectos laborais relacionados a horas e turnos de trabalho, hora extra, tempo de trabalho na empresa e estilo de vida.

\section{MATERIAL E MÉTODO}

Trata-se de estudo epidemiológico transversal com análise estatística descritiva, realizado em indústria metalúrgica, em cidade com 50.602 habitantes, no interior do Estado de São Paulo.

Para coleta dos dados foi utilizado questionário com dados sociodemográficos, estilo de vida, dados laborais e de saúde, testado em aproximadamente 1600 trabalhadores, de diferentes empresas e setores, que abordou aspectos de saúde, estilo de vida e turnos e horário de trabalho ${ }^{(12)}$.

A população da empresa, no período de realização da pesquisa, era de 200 trabalhadores e a amostra foi constituída por 182, distribuídos no setor administrativo, produção, secretários e supervisores, com taxa de resposta de $91 \%$.

Foram incluídos no estudo os trabalhadores que aceitaram participar, que não estavam em período de férias, com afastamentos por atestados médicos e/ou outros tipos de afastamento durante o período de sua realização, tais como licença maternidade, paternidade, gala, entre outros.

A coleta de dados foi realizada no período de julho 2004 a janeiro/fevereiro 2005 e estendeu-se a todos os turnos de trabalho e horário administrativo: turno da manhã (5h20 às $13 \mathrm{~h} 40$ ), tarde ( $13 \mathrm{~h} 40$ às $22 \mathrm{~h}$ ) e noturno ( $22 \mathrm{~h}$ às $5 \mathrm{~h} 20)$. Para os trabalhadores da área de produção (operadores de máquina, por exemplo) o questionário foi aplicado mediante contato direto e foi entregue aos do setor administrativo e escritório 
para que os mesmos respondessem. A estatística descritiva e os testes estatísticos foram realizados utilizando o Programa $\mathrm{SAS}^{\circledast}$ 9.2.

O estudo foi aprovado pelo Comitê de Ética da Universidade Estadual de Campinas (SP) como adendo sob o protocolo 286/2004 e autorizado pelos indivíduos por meio da assinatura do Termo de Consentimento Livre e Esclarecido.

\section{RESULTADOS E DISCUSSÃO}

São apresentadas abaixo as principais variáveis sociodemográficas dos trabalhadores entrevistados.

Tabela 1 - Frequência de algumas variáveis sociodemográficas e estilo de vida dos trabalhadores de indústria metalúrgica do interior do estado de

São Paulo, 2005.

\begin{tabular}{|c|c|c|c|}
\hline Variáveis & Categorias & $\mathbf{n}$ & $\%$ \\
\hline Sexo & $\begin{array}{l}\text { Feminino } \\
\text { Masculino }\end{array}$ & $\begin{array}{c}44 \\
138\end{array}$ & $\begin{array}{l}24,2 \\
75,8\end{array}$ \\
\hline Faixa etária (anos) & $\begin{array}{l}\text { Até } 20 \\
20 \text { a } 29 \\
30 \text { a } 39 \\
40 \text { a } 49 \\
\geq 50\end{array}$ & $\begin{array}{c}5 \\
67 \\
56 \\
46 \\
8\end{array}$ & $\begin{array}{c}2,7 \\
36,8 \\
30,8 \\
25,3 \\
4,4\end{array}$ \\
\hline Situação conjugal & $\begin{array}{l}\text { Solteiro } \\
\text { Casado/vive com companheiro } \\
\text { Separado/divorciado/viúvo }\end{array}$ & $\begin{array}{c}53 \\
117 \\
12\end{array}$ & $\begin{array}{c}29,1 \\
64,3 \\
6,6\end{array}$ \\
\hline Filhos & $\begin{array}{l}\text { Sim } \\
\text { Não }\end{array}$ & $\begin{array}{c}116 \\
66\end{array}$ & $\begin{array}{l}63,7 \\
36,2\end{array}$ \\
\hline Escolaridade & $\begin{array}{l}<8 \text { anos } \\
8 \text { a } 10 \text { anos } \\
11 \text { a } 14 \text { anos } \\
\geq 15 \text { anos }\end{array}$ & $\begin{array}{c}27 \\
30 \\
101 \\
24\end{array}$ & $\begin{array}{l}14,8 \\
16,5 \\
55,5 \\
13,2\end{array}$ \\
\hline Continua estudando & $\begin{array}{l}\text { Sim } \\
\text { Não }\end{array}$ & $\begin{array}{c}40 \\
142\end{array}$ & $\begin{array}{l}22 \\
78\end{array}$ \\
\hline Atividade física & $\begin{array}{l}\text { Sim } \\
\text { Não }\end{array}$ & $\begin{array}{c}100 \\
82\end{array}$ & $\begin{array}{l}55 \\
45\end{array}$ \\
\hline Atividades de lazer & $\begin{array}{l}\text { Sim } \\
\text { Não }\end{array}$ & $\begin{array}{c}161 \\
21\end{array}$ & $\begin{array}{l}88,4 \\
11,5\end{array}$ \\
\hline Tabagismo & $\begin{array}{l}\text { Sim } \\
\text { Não }\end{array}$ & $\begin{array}{c}32 \\
150\end{array}$ & $\begin{array}{l}17,5 \\
82,5\end{array}$ \\
\hline Ingestão de bebida alcoólica & $\begin{array}{l}\text { Sim } \\
\text { Não }\end{array}$ & $\begin{array}{c}109 \\
73\end{array}$ & $\begin{array}{l}59,9 \\
40,1\end{array}$ \\
\hline Total & & 182 & 100 \\
\hline
\end{tabular}

A amostra foi constituída por 182 trabalhadores de diferentes setores da empresa, distribuídos entre a fábrica e o escritório administrativo, dos quais 138 (75,8\%) eram homens e $44(24,2 \%)$, mulheres, com idade entre 16 e 58 anos e idade média de 33,8 anos (SD 9,5). Parcela considerável dos trabaIhadores tinha menos que 30 anos de idade (39,6\%).

Pesquisas realizadas com trabalhadores metalúrgicos apresentaram média de idade semelhante ao presente estudo, de 33 anos (mediana de 32 anos e desvio padrão de 9,8 anos) e de 35,9 anos, respectivamente ${ }^{(3,13)}$. Outros autores ${ }^{(14-15)}$ também encontraram média de idade semelhante, de 34,5 e 38,6 anos respectivamente. Pesquisa ${ }^{(16)}$ mostrou que a maior parte dos trabalhadores tinha entre 20 a 29 anos $(41 \%)$ e 30 a 39 anos (37\%). Outra investigação realizada em empresa de grande porte, do ramo metalúrgico em Caxias do Sul, RS identificou idade média superior, de 44,3 anos (desvio padrão de 10,2 anos) ${ }^{(17)}$.

A jornada de trabalho na empresa estudada era de 44 horas semanais, com seis dias de trabalho por semana, em três turnos fixos de trabalho. A grande porcentagem de homens pode ser justificada pelo tipo de trabalho realizado. A maioria das mulheres atuava nos setores internos (escritórios e recursos humanos), sendo a minoria encontrada nas máquinas.

Em estudo(13) realizado na maior indústria metalúrgica de Canoas-RS, foi identificado, em relação ao sexo, número menor de mulheres $9,7 \%$ que atuava, de modo semelhante ao encontrado no presente estudo, somente em setores administrativos. Autores ${ }^{(14,16)}$ também obtiveram em seus estudos, em metalúrgicas, porcentagem maior de homens correspondendo a $84,8 \%$ e $62,5 \%$ respectivamente.

Observa-se também que a maioria dos trabalhadores era casada/vivia com companheiro $(64,3 \%)$ e tinha filhos $(63,7 \%)$, sendo que destes, aproximadamente $80 \%$ tinham um ou dois filhos. Dado semelhante foi encontrado em outra pesquisa na qual, dos metalúrgicos estudados, $64,6 \%$ eram casados $^{(13)}$. Isto pode estar relacionado ao maior controle do número de filhos, mas deve-se levar em consideração que muitos deles ainda são jovens existindo maior possibilidade de terem mais filhos posteriormente. O número de horas despendidas na educação dos filhos era, em média, de 3,3 horas por dia.

Em relação às tarefas domésticas 131 (72\%) realizavam-nas utilizando em média 2,2 horas por dia. Quanto a este dado é importante destacar que a maioria da amostra foi composta por homens e que parte dos mesmos realizava atividades na casa. A maioria residia em casa própria $154(84,6 \%) ; 36,3 \%$ das residências tinham cinco cômodos e $67 \%$ apenas um banheiro. 
A baixa escolaridade de parte dos trabalhadores (14,8\%) pode estar relacionada principalmente a idade em que começaram a trabalhar, pois, para 95 foi antes dos 14 anos. Entre os 27 trabalhadores com menos de oito anos de escolaridade, 20 começaram a trabalhar antes dos 14 anos de idade. Dos que tinham quatro anos ou menos de escolaridade, a faixa etária variou de 28 a 57 anos.

Quarenta trabalhadores estavam estudando no período da pesquisa $(22 \%)$, a grande maioria terminando o curso superior $24(60 \%)$, seguida de cursos complementares (inglês/ espanhol), sete $(17,5 \%)$. Quatro (10\%) estavam cursando o ensino médio e $5 \%$, a sexta série. Havia ainda dois trabalhadores (5\%) fazendo curso técnico e um $(2,5 \%)$ na pós-graduação. O horário de realização dos cursos era basicamente noturno $(90 \%)$. Em relação à escolaridade, estudo(13) verificou que $50 \%$ dos respondentes possuíam ensino médio completo, seguido por 23,5\% que possuíam ensino superior incompleto.

Eram tabagistas $17,5 \%$ da amostra estudada, com média de 13,3 cigarros por dia. Este dado é menor do que o encontrado em estudo(18) realizado com metalúrgicos, na cidade de Itapira-SP, no qual 22,5\% dos 142 sujeitos entrevistados eram tabagistas. Outra pesquisa ${ }^{(15)}$ com metalúrgicos também mostrou que $45,4 \%$ referiram que eram ou tinham sido tabagistas. É importante destacar que 20,5\% das mulheres e 16,7\% dos homens fumavam. Esta porcentagem é superior a média brasileira segundo pesquisa do Ministério da Saúde, por meio do Instituto Nacional de Câncer (Inca) ${ }^{(19)}$, na qual 18,8\% da população brasileira era fumante $(22,7 \%$ dos homens e $16 \%$ das mulheres). No presente estudo pode-se verificar maior quantidade de mulheres tabagistas. Entre os que relataram já ter fumado anteriormente a média de anos que pararam de fumar foi de 11,6 anos, tendo fumado em média durante 10,9 anos, 17,6 cigarros /dia e um deles referiu não saber.

A maioria fazia uso de bebida alcoólica $(59,9 \%)$, sendo que, destes, $86,2 \%$ ingeriam cerveja e, 6,4\%, cerveja e vinho. Em outro estudo ${ }^{(18)}$ foi identificado menor percentual de trabaIhadores que ingeriam bebida alcoólica - 47,2\% e outro autor $^{(15)}$ encontrou percentual semelhante, pois $64,6 \%$ referiam utilizá-la com frequência.

Pouco mais da metade dos sujeitos (55\%) referiu realizar atividade física fora do trabalho sendo o esporte mais praticado o futebol $(37,5 \%)$, provavelmente devido ao fato da maior parte dos entrevistados ser do sexo masculino. Pesquisa ${ }^{(18)}$ encontrou valores maiores em empresa metalúrgica que estudou, pois $71,1 \%$ praticavam algum tipo de atividade física, assim como outra investigação ${ }^{(13)}$ que também verificou valores maiores dos trabalhadores que realizavam atividade física, $77,6 \%$. A segunda atividade física com maior frequência foi a caminhada $(27,5 \%)$.

Dos trabalhadores estudados, $161(88,5 \%)$ realizavam atividade de lazer sendo a mais frequente assistir TV $(14,4 \%)$, seguida de passear $(12,1 \%)$, ouvir música $(11,3 \%)$, visitar família $(8,8 \%)$, sair com os amigos $(7,8 \%)$, almoçar /jantar fora $(7,3 \%)$, frequentar igreja $(7 \%)$, pescar $(6 \%)$ e leitura de jornal/ revista $(5,2 \%)$.

A média do tempo de trabalho na empresa foi de 9,5 anos e, no setor, sete anos. Estudos ${ }^{(15,17)}$ identificaram valores mais elevados entre trabalhadores metalúrgicos, sendo a média de trabalho nas indústrias de 15,2 anos, e 13,5 anos respectivamente.

Na empresa estudada a Fábrica era composta pelos setores: Expedição, Extrusão, Trefila, Medição/embalagem, Cordagem, Montagem de cabos, Torção, Trançadeira, Controle de qualidade, Manutenção (elétrica/ Segurança do trabalho) e o Escritório Administrativo, na qual faziam parte os setores de: CCR (Call Center), Compras, Vendas e Contabilidade. Dos entrevistados 22,5\% (41) eram do setor administrativo. Entre os trabalhadores da fábrica, $79(43,4 \%)$ referiram ser operadores de máquina.

Em relação à média de horas de trabalho por dia, os trabalhadores do turno da manhã e da tarde trabalhavam 8h20, com 40 minutos de intervalo para refeição e lanches. Os do turno noturno trabalhavam 7 h20 por dia com intervalo também de 40 minutos para lanche. Aos sábados, os do turno da manhã e tarde trabalhavam 5 h40 por dia; os do turno noturno não trabalhavam aos sábados, e iniciavam a jornada as $23 \mathrm{~h} 40$ no domingo.

O número médio de horas de sono durante a semana foi de $6,8 \mathrm{~h}$ e de $8 \mathrm{~h}$ nos dias de folga e final de semana. Embora a maioria tenha relatado se sentir descansado e cheio de energia após acordar $(n=126,69,2 \%)$, parte dos trabalhadores respondeu negativamente a esta questão $(n=55,30,2 \%)$. Este é um dado relevante, pois a jornada de trabalho era de 44 horas semanais, acrescido ao fato de que aproximadamente $3 / 4$ dos trabalhadores realizavam horas extras e, com a presença do cansaço, a chance de ocorrer acidentes de trabalho pode aumentar. A grande maioria $(n=132)$ relatou que estava realizando hora extra há vários meses $(72,5 \%)$, para atender os prazos de entrega em decorrência do aumento no número de pedidos e encomendas da produção. A média de meses de horas extras no ano anterior foi de 6,3 meses, e a média do número de horas extras foi 24,4 h por mês e $96,1 \%$ recebiam pelas atividades extras em dinheiro. Foi verificada relação estatística entre não dormir bem e ter realizado horas extras no último ano $(\mathrm{p}=0.04)$.

Outro dado relevante foi a média de idade em que os mesmos começaram a trabalhar, correspondendo há 13,4 anos. Tal fato já foi citado anteriormente sendo relacionado à baixa escolaridade. Como o início do trabalho foi precoce, geralmente para ajudar a família, muitos deles deixaram de estudar. Metade dos entrevistados relatou já ter ficado desempregado, em média, durante 12,8 meses. Um pequeno número de pessoas tinha outro emprego ou outros tipos de atividades com pequenos ganhos avulsos, $12(6,6 \%)$. A grande maioria referiu ter crença religiosa $170(93,4 \%)$, sendo a maior parcela de católicos 150 (88,2\%) e, mais da metade (59,4\%), frequentava missa ou culto.

A classificação do IMC (Índice de Massa Corporal) dos trabalhadores pesquisados é apresentada na Tabela 2 .

A OMS (Organização Mundial de Saúde, 2011)(20) classifica os valores do IMC da seguinte forma: < 18,5 magreza, valores entre 18,5 - 24,99 saudável, 25,0 - 29,99 sobrepeso/ pré obesidade, 30,0 - 34,99 obesidade grau I, 35,0 - 39,99 obesidade grau II e $\geq 40,0$ obesidade grau III (mórbida). 
Tabela 2 - Distribuição dos trabalhadores de indústria metalúrgica do interior do estado de São Paulo conforme Índice da Massa Corporal, 2005.

\begin{tabular}{ccccc}
\hline IMC* & Masculino & $\%$ & Feminino & $\%$ \\
\hline$<18,5$ & 3 & 2,2 & 3 & 6,8 \\
$18,5-24,99$ & 69 & 50 & 31 & 70,4 \\
$25-29,99$ & 54 & 39,1 & 8 & 18,2 \\
$30-34,99$ & 9 & 6,5 & 2 & 4,5 \\
$35-39,99$ & 3 & 2,2 & 0 & 0 \\
$>=40,0$ & 0 & 0 & 0 & 0 \\
\hline Total & 138 & 100 & 44 & 100
\end{tabular}

*IMC: Índice de Massa Corporal, determinado pela divisão da massa do indivíduo pelo quadrado de sua altura, onde a massa está em quilogramas e a altura está em metros

Quanto ao IMC, 54,9\% dos trabalhadores apresentaram valores dentro do limite considerado saudável (50\% dos homens e $70,4 \%$ das mulheres), mas, grande parcela $(41,75 \%)$ apresentou sobrepeso ou obesidade. Sobrepeso e obesidade também foram observados por pesquisa ${ }^{(14)}$, em 53\% dos trabalhadores, mas principalmente sem a obesidade abdominal $(65,1 \%)$.

Em relação à média de tempo de ida e volta para o trabaIho obteve-se 32,5 minutos. Tal dado é explicado pelo fato de ser uma cidade de pequeno porte e do interior do Estado, na qual não é comum o trânsito. A maioria ia para o trabalho de ônibus fretado pela empresa $(n=84,46,1 \%)$; seguido por carro $(n=40,22 \%)$; bicicleta $(n=17,9,3 \%)$; a pé $(n=6,3,3 \%)$ e uma pessoa $(0,5 \%)$ que utilizava bicicleta ou ia a pé e outra que utilizava carro ou ônibus.

Quando indagados sobre a sua saúde comparada à de outras pessoas da mesma idade, $93(51,1 \%)$ relataram estar igual; 70 (38,5\%), melhor; $15(8,2 \%)$ muito melhor; e quatro $(2,2 \%)$, um pouco pior. Quando comparado atividade física e saúde em relação a outras pessoas da mesma idade houve significância estatística ( $p=0.0405)$ e $80 \%$ dos que consideraram sua saúde muito melhor realizavam atividade física.

Embora a maioria dos entrevistados 112 (61,5\%) referiu não ter tido episódio de dor nos últimos seis meses, deve ser considerado o fato de que $70(38,5 \%)$ relataram a presença de dor nos últimos seis meses, sendo os locais de maior frequência: $18(25,7 \%)$ região lombar, seguido de $12(17,1 \%)$ coluna e, sete, $(10 \%)$ cabeça. Em relação à dor na última semana da data da entrevista, um quarto dos entrevistados relatou ter tido dor $(n=45,24,7 \%)$, e os locais mais citados foram: costas 12 $(26,7 \%)$, cabeça $8(17,8 \%)$, e coluna/pescoço com $4(8,9 \%)$ cada. Pesquisa ${ }^{(13)}$ demonstrou que $75,2 \%$ dos trabalhadores relataram algum tipo de sintoma osteomuscular (dor, desconforto ou dormência) nos últimos doze meses; 53,3\% nos últimos sete dias, sendo que $38,5 \%$ já tiveram afastamento devido ao problema.

Estudo $^{(10)}$ sobre a qualidade de vida de trabalhadores em empresa metalúrgica, encontrou que as 56 queixas principais, possivelmente estavam relacionadas ao trabalho, considerando a natureza dos movimentos e posturas adotadas nos postos de trabalho e condições do ambiente. Destacaram-se as dores musculares, dor de cabeça e zumbido nos ouvidos.

Quando indagados sobre presença de doença nos últimos 12 meses, 43 (23,6\%) responderam afirmativamente: Hipertensão Arterial Sistêmica (HAS) com 10,2\% $(n=6)$, seguida de gripe $(n=3,5,1 \%)$ e colesterol, coluna, gastrite, lesão por esforço repetitivo (LER), ácido úrico e coluna, sendo dois em cada $(3,4 \%)$.

Pesquisa(14) mostrou que "os trabalhadores foram distribuídos quase igualmente em termos de presença ou ausência de doenças crônicas e/ou sintomas (51,2\% sim)". Dor nas costas foi o mais comum $(30,9 \%)$.

Quanto à realização de consulta médica, a maior parte dos entrevistados respondeu afirmativamente $(n=156,85,7 \%)$ e referiu ter realizado exame médico periódico na empresa, além do exame auditivo. Quanto às especialidades médicas as mais frequentemente consultadas por 156 trabalhadores foram em ordem decrescente: clínico geral (51,3\%); ginecologista $(5,8 \%)$; oftalmologista $(4,5 \%)$ e ortopedista, cardiologista e otorrinolaringologista $(3,8 \%)$.

Dos 182 trabalhadores, 58 (31,9\%) referiram fazer uso de algum medicamento.

Intervenções bem sucedidas no ambiente de trabalho incluem além da disponibilização de recursos adequados, a avaliação e monitoramento no âmbito multidisciplinar, bem como a participação dos trabalhadores em todo o processo(21).

O médico suíço Henry Sigerist, já em 1946, considerava que a promoção da saúde, em seu sentido ampliado englobava educação, boas condições de vida e trabalho, formas de repouso e lazer ${ }^{(1)}$. É um conjunto de fatores mais abrangentes que se inter-relacionam sendo, portanto, indispensável uma boa alimentação, sono adequado, prática de atividades física e de lazer para que o indivíduo sinta-se disposto, com energia e condições adequadas de realizar o trabalho e não apenas às condições relacionadas diretamente ao processo de trabalho.

\section{CONCLUSÃO}

Como evidenciaram os resultados deste estudo, a maioria dos trabalhadores metalúrgicos era do sexo masculino (75,8\%), com média de 33,8 anos de idade e início precoce no trabalho, pois 95 deles começaram a trabalhar antes dos 14 anos de idade, o que afetou sua escolaridade. Muitos começaram muito cedo para ajudar em casa, deixando quase sempre os estudos. A maioria dos trabalhadores era casada/vivia com companheiro $(64,28 \%)$ e tinha filhos $(63,7 \%)$, sendo que destes, aproximadamente $80 \%$ tinham um ou dois filhos. Tal dado pode estar relacionado ao controle do número de filhos, mas tendo em vista a média de idade dos trabalhadores deve-se levar em conta que podem ter mais filhos posteriormente. Outro dado bastante significativo e positivo em relação aos aspectos socioeconômicos é que $84,6 \%$ tinham casa própria.

A maioria dos trabalhadores trabalhava na fábrica e, destes, $79(43,41 \%)$ referiram ser operadores de máquina. Dos entrevistados 22,53\% (41) eram do setor administrativo. Em 
relação à atividade física $45 \%$ referiram não realizá-la (45\%), o que pode estar relacionado ao fato que parcela significativa dos trabalhadores tinha IMC acima dos padrões considerados normais. $\mathrm{O}$ local mais frequente em relação à dor auto referida foi a região lombar $(26,7 \%)$ e tal fato pode estar relacionado à postura no local de trabalho e ao tipo de trabalho realizado.

O perfil sociodemográfico permite um melhor conhecimento da população estudada a fim de traçar metas e planejar ações com base nas informações levantadas. Dentre os achados deste estudo, destaca-se o fato de que uma parcela significativa referiu não se sentir descansado e cheio de energia (30,2\%). Isto pode estar relacionado às horas extras, pois $72,5 \%$ referiram realizá-las. Realizando horas extras, o trabalhador pode, muitas vezes, deixar de realizar atividades básicas e essenciais a saúde, tais como: horas de sono e alimentação adequada; o que pode prejudicar sua saúde e influenciar seu desempenho.

A área da saúde do trabalhador encontra-se em processo que objetiva a proteção e promoção à saúde, tendo como referência não apenas os trabalhadores, mas, também o meio em que estão inseridos e as condições de saúde e educação. Assim, é possível inferir que o planejamento de ações por parte das equipes de saúde do trabalhador é essencial para as organizações seja voltada para educação com o desenvolvimento de programas que estimulem a melhor integração individual e social e palestras educativas; seja por meio do controle e monitoramento do arranjo físico e organizacional do trabalho, como também execução de ações preventivas e de promoção como a realização periódica de exames, campanhas preventivas, implantação e controle do Programa de Conservação Auditiva (PCA), entre outros eventos que possam estimular e proteger a saúde dos trabalhadores.

A articulação da promoção da saúde no trabalho é fundamental no processo de execução de ações voltadas a saúde do trabalhador, considerando este como sujeito ativo capaz de contribuir para transformação de sua própria saúde e do meio no qual se insere.

Frente ao exposto, e devido à escassez de estudos sobre metalúrgicos na literatura, sugere-se que haja uma melhor exploração do perfil dessa população, que novos estudos sejam realizados a fim de identificar e analisar a situação de saúde dos trabalhadores para a definição de prioridades na formulação de estratégias e no planejamento e implementação de ações multiprofissionais, interdisciplinares e intersetoriais efetivas, que possam contribuir para mudanças e melhorias relacionadas a promoção de saúde, condições de vida e trabalho.

Ressalte-se, por fim, que os resultados tabulados foram encaminhados à empresa para serem utilizados no planejamento das atividades de promoção à saúde do trabalhador.

\section{REFERÊNCIAS}

1. Cavalcante CAA, Nóbrega JAB, Enders BC, Medeiros SM. Promoção da saúde e trabalho: um ensaio analítico. Rev Eletrônica de Enferm [periódico na internet] 2008 [acesso em 15 fev 2013];10(1):241-248. Disponível em: http://www.fen.ufg.br/revista/v10/n1/v10n1a23.htm.

2. Gonçalves CGO, Dias A. Três anos de acidentes do trabaIho em uma metalúrgica: caminhos para seu entendimento. Ciênc Saúde Coletiva [periódico na Internet] 2011 fev [acesso em 29 jun 2011];16(2): 635-646. Disponível em: http://homolog.scielo.br/scielo.php?script = sci_arttext \&pid $=$ S1413-81232011000200027\&lng $=$ pt.

3. González BZ, Sierra VP, Martínez JIV, Muraira YC, Ramos CV. Disminución auditiva de trabajadores expuestos a ruido en una empresa metalmecánica. Cienc Trab [periódico na internet] 2010 Ene.-Mar [acesso em 14 fev 2013];12(35):233-236. Disponível em: http://bases.bireme.br/cgi-bin/wxislind.exe/iah/online/?lsisScript =iah/iah. xis\&src $=$ google $\&$ base $=$ LILACS\&lang $=p \&$ nextAction $=$ I $n k \&$ exprSearch $=559599$ \&indexSearch $=$ ID

4. Chaves SCL, Santana VS, Leão ICMd, Santana JNd, Almeida Lacerda LMAd. Determinantes da implantação de um programa de segurança e saúde no trabalho. Rev Panam Salud Publica. 2009;25(3):204-212.

5. Costa CB, Gama WU, Momensohn-Santos TM. Eficácia do Protetor Auditivo de Inserção em Programa de Prevenção de Perdas Auditiva. Arq Int Otorrinolaringol 2009;13(3):281-286.

6. González MC, Ahumada HT, Martínez MR. Percepción del riesgo sobre protección y pérdida auditiva en trabajadores expuestos a ruido en el trabajo. Cienc Trab [periódico na internet] 2009 Ene-Mar [acesso em $14 \mathrm{fev}$ 2013];11(31):1-4. Disponível em: http://bases.bireme.br/ cgi-bin/wxislind.exe/iah/online/? lsisScript $=$ iah/iah.xis\&sr $\mathrm{C}=$ google\&base $=$ LILACS\&lang $=$ p\&nextAction $=$ Ink\&ex prSearch $=523032$ \&indexSearch $=$ ID

7. EUROPEAN UNION [homepage na internet]. [acesso em 26 jun 2005]. Disponível em http://www.eu.int.

8. Ogido R, Costa EA, Machado HC. Prevalência de sintomas auditivos e vestibulares em trabalhadores expostos a ruído ocupacional. Rev Saúde Pública [periódico na internet]. 2009 abr [acesso em 29 jun 2011 ];43(2):377-380. Disponível em: http://www.scielo.br/scielo.php?script =sci arttext\&pid = S0034-89102009000200021\&lng = en.

9. Lacerda A, Garofani VG, Ribeiro L, Marques JM. Efeitos auditivos em operadores de empilhadeira. Rev Soc Bras Fonoaudiol [periódico na Internet]. $2010 \mathrm{dez}$ [acesso em 29 jun 2011];15(4):514-519. Disponível em: http://homolog.scielo.br/scielo.php?script = sci_arttext\&pid $=$ S1516$-80342010000400007 \& \operatorname{lng}=$ pt.

10. Dyniewicz AM, Moser AD, Santos AF, Pizoni H. Avaliação da qualidade de vida de trabalhadores em empresa metalúrgica: um subsídio à prevenção de agravos à saúde 200. Fisioter Mov 9;22(3):547-466.

11. Fernandes ACPI, Monteiro MI. Capacidade para o trabaIho entre trabalhadores de um condomínio de empresas de alta tecnologia. Rev Bras Enferm [periódico na internet]. 2006 dez [acesso em 29 jun 2011]; 59(6):752-756. Disponível em : http://www.scielo.br/scielo.php?script=sci 
arttext\&pid = S0034-71672006000600006\&lng = en.

12. Monteiro MI. Instrumento para coleta de dados. Campinas: Universidade Estadual de Campinas, 1996.

13. Picoloto D, Silveira E. Prevalência de sintomas osteomusculares e fatores associados em trabalhadores de uma indústria metalúrgica de Canoas - RS. Ciênc Saúde Coletiva [periódico na Internet]. 2008 abr [acesso em 29 jun 2011 ];13(2):507-516. Disponível em: http://www. scielo.br/scielo.php?script =sci_arttext\&pid $=$ S1413$-81232008000200026 \& \operatorname{lng}=p t$.

14. Höfelmann DA, Blank N. Identification of confounders in the association between self-reported diseases and symptoms and self-rated health in a group of factory workers. Cad Saúde Pública [periódico na internet]. 2008 maio [acesso em 29 jun 2011];24(5):983-992. Disponível em: http://www.scielo.br/scielo.php?script=sci arttext\&pid $=$ S0102-311X2008000500005\&Ing $=$ en

15. Ubrig-Zancanella MT, Behlau M. Relação entre ambiente de trabalho e alteração vocal em trabalhadores metalúrgicos. Rev Soc Bras Fonoaudiol. [periódico na internet] 2010 [acesso em 29 jun 2011];15(1): 72-79. Disponível em: http://www.scielo.br/scielo.php?script =sci arttext\&pid $=$ S1516-80342010000100013\&lng $=$ en.

16. Igami TZ, Schellini SA, Matai O, Padovani CR. Condição ocular entre trabalhadores de uma indústria metalúrgica brasileira. Rev Bras Oftalmol. [periódico na internet]. 2008 out [acesso em 29 jun 2011]; 67(5):214-219. Disponível em: http://www.scielo.br/scielo.php?script =sci arttext\&pid $=$ S0034-72802008000500003\&lng $=$ en.

17. Ferreira AV, Aita ADC, Siqueira LP. Ocorrência de perda auditiva por nível de pressão sonora elevado em trabaIhadores de uma indústria do ramo metalmecânico de Caxias do Sul-RS. Distúrb comun [periódico na internet] 2012 Ago [acesso em 14 fev 2013];24(2). Disponível em: http://bases.bireme.br/cgi-bin/wxislind.exe/iah/ online/? IsisScript $=$ iah/iah $. x i s \& s r c=$ google $\&$ base $=$ LILAC S\&lang $=p \&$ nextAction $=$ Ink\&exprSearch $=655167$ \&inde $\mathrm{xSearch}=\mathrm{ID}$

18. Ornellas TCF. Capacidade para o trabalho entre trabalhadores de empresa metalúrgica de uma cidade do interior paulista. Campinas. Dissertação [Mestrado em Enfermagem] -Universidade Estadual de Campinas/UNICAMP; 2004.

19. Ministério da Saúde [homepage na internet].Tabagismo [acesso em 13 mar 2011]. Disponível em: http:// portal.saude.gov.br/portal/saude/visualizar texto. cfm?idtxt $=29479$.

20. World Health Organization. Body Mass Index (BMI) Classification. [homepage na internet] [acesso em 13 mar 2011]. Disponível em: http://apps.who.int/bmi/index. jsp? introPage $=$ intro_3.html.

21. OSHA- Occupational Health and Safety Assessment Services. Distúrbios Osteomusculares relacionados ao trabaIho: relatório de prevenção. [homepage na internet] 2008 [acesso em 15 fev 2013]. Disponível em: https://osha.europa.eu/en/publications/factsheets/78. 